\title{
РЕГИОНАЛЬНЫЕ ОСОБЕННОСТИ ДИНАМИКИ ЕСТЕСТВЕННОГО ДВИЖЕНИЯ НАСЕЛЕНИЯ САРАТОВСКОЙ ОБЛАСТИ ЗА ПОСЛЕДНИЕ 15 ЛЕТ
}

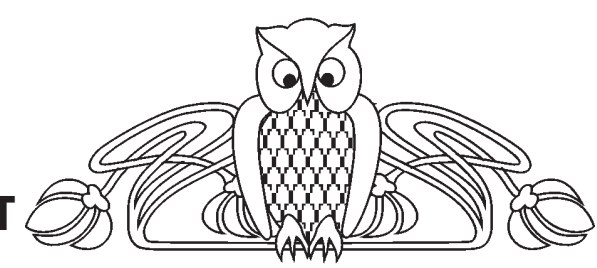

\section{О.В. Терентьева, С.С. Троцко 1 \\ Саратовский государственный университет, кафедра экономической географии ${ }^{1}$ Саратовский государственный университет, географический факультет (выпускник 2005 г.) E-mail: ovterenteva@mail.ru}

Статья посвящена демографической ситуации в Саратовской области. В ней рассматриваются динамика рождаемости, смертности и естественного прироста по районам, городам и области в целом, анализируются причины этого и возможные последствия. В статье использованы статистические данные за 1989, 1995, 1996, 1997, 1998, 2002 и 2003 гг. The Regional Particularities of the Population Natural Movement
of the Saratov Region for the Past 15 Year

\section{O.V. Terenteva, S.S. Trotzko}

The article is about the demographic situation of the Saratov region. The birthrate, the deathrate and the natural increase of the population of the districts, towns and the region in whole are considered, the causes conducive to its and the possible results are analyzed. There are many statistical data of the 1989, 1995, 1996, 1997, 1998, 2002 2003 years.

Переломным для страны стал 1991 год. Произошедшие реформы принесли коренные изменения в экономике, политическом строе, сознании, традициях и укладе жизни людей. Прошедшие 15 лет дают возможность выявить тенденции, как сформировавшиеся до этого периода, так и ставшие результатом социально-экономических преобразований. В связи с этим представляется необходимым на примере Саратовской области проследить изменения в такой важной и чувствительной сфере демографии, как воспроизводство населения.

Саратовская область занимает площадь в 100,2 тыс. км ${ }^{2}$ и состоит из 38 районов, в которых сосредоточенно 18 городов, 30 посёлков городского типа и 1752 сельских населённых пункта. По последним данным в области проживает 2643,6 тыс. постоянных жителей, плотность населения составляет 26,5 чел. на км² [1]. Из них большая часть является городским населением $(73,5 \%)$, в то время как сельское население составляет только $26,5 \%$. В половозрастной структуре населения области в 2002 г. преобладали женщины $-53,3 \%$ [2].

За период с 1995 по 2002 г. численность населения трудоспособного возраста увеличилась с 57,2 до 60,0\%, лиц старших возрастов - с 20,8 до
$22,1 \%$, в то время как численность детей сократилась с 22,0 до 17,9\%. В целом с 2003 по 2004 г. число жителей области уменьшилось на 19,9 тыс. человек.

Процесс сокращения численности населения области начался с 1992 г. и явился следствием социально-экономических и политических изменений в стране. Переход России к новым рыночным отношениям ускорил формирование негативных демографических трендов в сфере рождаемости и семьи, к которым можно отнести преобладание семей с одним - двумя детьми, снижение брачности, рост внебрачной рождаемости, сокращение интенсивности деторождений, увеличение количества абортов и т.д. Кроме того, был окончательно разрушен патриархальный семейный уклад, произошли изменения в восприятии семьи как социального института. Тем не менее наиболее ощутимой причиной изменения уровня рождаемости является уровень материального благополучия семей, который в настоящее время оставляет желать лучшего.

Все это способствовало резкому падению рождаемости, сократившейся в период с 1988 по 1997 г. почти в 2 раза (с 16,5 до 7,9\%о) [3]. После незначительного колебания общего уровня рождаемости в 1998-1999 гг. в 2000 г. началось постепенное увеличение числа родившихся. Особенно высокий прирост произошёл в 2002 г., когда показатель рождаемости увеличился с 8,2 (2001 г.) до 8,7\%, а к 2003 году он уже составил $9,1 \%$ [1]. По прогнозам рост рождаемости будет продолжаться до 2009 г., после чего начнётся спад. Увеличение числа родившихся обусловлено главным образом не ростом уровня рождаемости (суммарный коэффициент рождаемости сохранился на прежнем уровне - 1,1 \%о (при необходимых для воспроизводства 2,15\%о)) [4], а влиянием двух основных причин:

1) увеличением количества рождений у женщин в возрасте старше 25 лет, связанным с отложенными ими деторождениями в начале 90-х гг. из-за нестабильной ситуации в стране;

2) воздействием демографической волны из прошлого: в 1981-1982 гг. был принят комплекс мер государственной поддержки семьям с детьми, что в настоящее время привело к увеличению числа женщин, возраст которых наиболее благоприятен для рождения детей (20-29 лет).

При рассмотрении показателя рождаемости в территориальном аспекте можно отметить, что уже с 1988 г. в области начала проявляться тен- 
денция к снижению числа деторождений. Так, с 1989 по 1996 г. резкое уменьшение рождаемости наблюдалось во всех крупных городах и районах области. Наиболее значительное оно было преимущественно в левобережных районах (падение рождаемости свыше 8\% было зарегистрировано в Аткарском, Балаковском, Дергачевском, Екатериновском, Марксовском, Перелюбском, Ровенском, Энгельсском районах). Иными словами, наиболее резко социально-экономические реформы ударили по благополучным районам Левобережья, сельское хозяйство которого получало огромные дотации на развитие.

В период с 1996 по 2003 г. спад рождаемости в области прекратился и начался обратный процесс - рост рождаемости. Несмотря на это, не все города и районы области коснулась данная тенденция. На территориях Левобережья и Правобережья с наиболее тяжелой социальноэкономической ситуацией на протяжении вышеуказанного периода рождаемость продолжала снижаться.

Необходимо отметить, что сокращение численности населения Саратовской области происходило на фоне высокого уровня смертности, который в период с 1989 по 2003 г. увеличился с 11,2 до 17,0\%. Высокая смертность способствовала снижению средней продолжительности предстоящей жизни, которая с 1989 по 2002 г. сократилась у мужчин на 4,8 лет и составила 59,7 лет, а у женщин - на 2,3 года, снизившись тем самым до 72,6 лет. В то же время эти показатели выше аналогичных общероссийских (мужчины - 58,9 лет, женщины - 72,0 года) [1].

В структуре причин смертности населения Саратовской области лидируют болезни системы кровообращения, несчастные случаи, отравления, травмы и новообразования. Смертность от болезней системы кровообращения занимала в 2002 г. первое место в структуре причин смертности населения. Число умерших по этой причине составило 25,4 тыс. человек (57,4\% от общего числа). Второе место в структуре смертности приходилось на несчастные случаи, отравления и травмы, от которых в 2002 г. скончалось 6,0 тыс. человек $(13,5 \%)$, что несколько ниже (на 4,3\%) уровня 2001 г., но более чем на треть выше, чем в 1998 г., когда эта группа причин находилась на третьем месте. В 2002 г. третье место занимали новообразования, от которых умерло 5,4 тыс. человек (12,3\%), что меньше уровня 1998 г. на 8,9\%.

Основная причина увеличения смертности и снижения средней продолжительности жизни в Саратовской области - низкий материальный уровень населения и как следствие невозможность большинства жителей области пользоваться качественным медицинским обслуживанием и покупать доброкачественные дорогие лекарства и продукты питания. Кроме того, не способствуют уменьшению смертности отсутствие здорового образа жизни, алкоголизм, ухудшение экологической обстановки и др.

Таким образом, из статистических данных видно, что в 2003 г. на территории области отмечался отрицательный естественный прирост населения. Такой процесс наблюдался практически во всех городах и районах Саратовской области, за исключением Александрово-Гайского района и пос. Светлый, что в первую очередь связано с возрастной структурой населения данных административных единиц. И в АлександровоГайском районе, и в посёлке Светлый отмечается повышенная доля детей и лиц трудоспособного возраста [2]. Однако причины такой возрастной структурной «аномалии» различны. Если в посёлке Светлый, который является местом проживания семей военнослужащих, это связано с преобладанием людей трудоспособного возраста (в основном 30-40 лет), то в Александрово-Гайском районе - с высоким удельным весом казахского населения, традиционно более многодетного, чем русские семьи.

Критическая ситуация сложилась в ряде городов и районов области (города Балашов, Вольск, Ртищево, Хвалынск, Аркадакский, Базарно-Карабулакский, Балашовский, Вольский, Воскресенский, Красноармейский, Лысогорский, Романовский, Ртищевский, Самойловский, Турковский и Хвалынский р-ны), где показатель естественной убыли населения находился на катастрофически высоком уровне: смертность превышала рождаемость в 2 раза, а отрицательный естественный прирост составлял более $-10 \%$. Такой показатель прироста населения связан с повышенным удельным весом людей старшего возраста и наблюдается на территориях с сильным оттоком молодежи в крупные города. Это ставит под сомнение перспективы социально-экономического развития данных административных единиц. «Лидерами» по этому показателю оказались Самойловский и Хвалынский районы, где естественная убыль населения составила в 2003 г. свыше - 6\%о.

Для сравнения, в 1989 г. естественное движение населения имело более благоприятную динамику. Это подтверждается тем, что в большинстве городов и районов области отмечался положительный естественный прирост. Однако уже тогда наблюдалась тенденция к убыли населения, которая проявилась в отрицательном естественном приросте ряда городов и районов Правобережья. В основном естественная убыль варьировалась в пределах от $-0,2$ до $-4,0 \%$, a eе максимальные значения не превышали $-6 \%$.

Семь лет спустя, в 1996 г., естественная убыль населения уже преобладала в большинстве городов и районов области, достигнув своего максимального значения $-12,6 \%$. Положительный естественный прирост сохранялся лишь в Александрово-Гайском, Озинском и Перелюбском районах области, а также в пос. Светлый. 
Таким образом, отрицательные показатели естественного движения в Правобережье в конце 80-х гг. лишь отразили тенденцию к формированию повсеместной убыли населения и были локальным проявлением общенационального явления. По данным статистики, коэффициент естественного прироста населения в России начал постепенно снижаться с 30-х гг. ХХ в. и к концу 80-х гг. уже имел низкое значение - 3,9\%о [5]. После вступления Российской Федерации в новые рыночные отношения в стране сложилась нестабильная социально-экономическая обстановка, приведшая к снижению среднего уровня жизни населения. Это способствовало активной убыли населения по всем регионам России, в том числе и в Саратовской области.

Если демографическая ситуация в области будет продолжать оставаться такой же сложной, то по прогнозам к 2050 г. численность населения области может сократиться с 2643,6 тыс. (2004 г.) до 1916,9 тыс. человек, т.е. на 726,7 тыс. человек. По мнению ряда исследователей, такие демографические сдвиги могут привести к замедлению экономического роста области из-за сокращения численности трудоспособного населения, к появлению новых требований к социальному обеспечению и медицинскому обслуживанию пожилых и старых людей, к увеличению демографической нагрузки на экономически активное население.

По мнению ученых, уже сейчас необходимо разрабатывать и осуществлять реальную демог- рафическую политику в Саратовской области, направленную на повышение рождаемости, снижение смертности и увеличение предстоящей продолжительности жизни населения. Однако воспроизводство населения - сложный процесс. Он включает экономические, социальные, политические, демографические, религиозные, психологические аспекты. Поэтому повлиять на рождаемость и брачность как составляющие воспроизводства населения лишь экономическими методами невозможно. Это же подтверждает и мировой опыт. Тем не менее снизить уровень смертности улучшением социально-экономической обстановки в области и проведением реальной демографической политики как на федеральном, так и на региональном уровнях - задача вполне выполнимая.

\section{Библиографический список}

1. Демографический ежегодник Саратовской области: Стат. сборник / Саратовский областной комитет государственной статистики. Саратов, 2003. 172 с.

2. Там же. Саратов, 2004. 160 c.

3. Там же. Саратов, 1997. $170 \mathrm{c}$.

4. Бестужев-Лада И.В. Депопуляция: Социальные проблемы // Демографические проблемы и семейная политика: Региональные проблемы: Материалы науч.-практ. конф. М., 1999. С. 11.

5. Население России за 100 лет: Стат. сборник / Госкомстат РФ. М., 1989. 222 с.

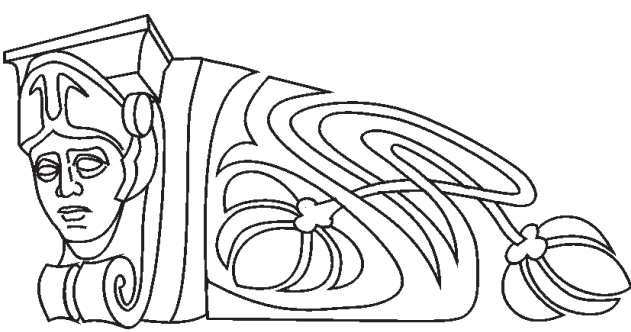

\section{О.Е. Нестерова}

Саратовский государственный университет, кафедра геоморфологии и геоэкологии E-mail: Nesterova@sgu.ru

В статье раскрывается понятие земельно-информационных систем, рассматривается их структура. Обосновывается связь между геоинформационными системами и ЗИС. Приводятся современные направления ЗИС в рамках геоинформационных систем.

\section{Geoinformation Systems as the Tool of Creation of Ground Information Systems}

\section{O.E.Nesterova}

The concept of ground-information systems is opened and their structure is considered in article. Communication between geoinformation systems and ground-information systems is proved. Modern directions ground-information systems are resulted within the framework of geoinformation systems.
В последнее время всё чаще возникает необходимость в достоверной и надёжной информации о земле как основе для планирования, развития и контроля за естественными ресурсами. Развитие общества значительно усилило давление на природную среду. Земля, которая является одним из основных источников материальных благ, в этой связи является важным объектом изучения и требует создания эффективной системы управления. Недооценка данного фактора приводит к негативным последствиям, примеры которых всем известны. Нерациональное использование в сельском хозяйстве земельных ресурсов приводит к таким стихийным бедствиям, как засуха, подтопление, эрозия грунтов. Лесные территории страдают от неограниченных вырубок. Уменьшается количество сельскохозяйственных угодий из-за роста населенных пунктов. Существуют определенные проблемы и в городском планировании. 